\title{
Neuroplasticity: a century-old idea championed by Adolf Meyer
}

\author{
— Cite as: CMAJ 2019 December 9;191:E1359-61. doi: 10.1503/cmaj.191099
}

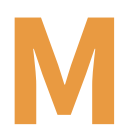

ost physicians today accept that subjective experience can change the adult brain organizationally or morphologically. As diverse evidence accumulates for neuroplasticity, researchers are exploring its origins in various intellectual and experimental antecedents. ${ }^{1,2}$ However, the concept is itself plastic, making its origins diffuse. Modifications of existing neural pathways, the formation of new connections and developmental or cerebral changes are all routinely termed "plasticity." It is commonly assumed that the concept emerged recently alongside the technology capable of measuring it, but the idea that the human nervous system could change throughout adulthood emerged more than a century ago.

One of the earliest champions of the idea was Adolf Meyer (1866-1950), the prominent chair of psychiatry at Johns Hopkins University from 1910 to 1941 (Figure 1). Meyer spearheaded efforts to transform psychiatry into a clinical discipline situated in university hospitals. He exercised unparalleled influence over the specialty's professional and pedagogical standards in the 20th century. As a theoretician, however, he was criticized and even ridiculed for his insistence that the mind-body divide was an erroneous construct that contradicted the principles of biology and the latest neuroscientific evidence. ${ }^{3}$

Today, it is clear that Meyer was pivotal in translating the concept of plasticity introduced by psychologist and philosopher William James in philosophical and biological terms into a framework for clinical psychiatry. In a 2009 article, Giovanni Berlucchi and Henry Buchtel identified James as the originator of the concept in his landmark 1891 textbook Principles of

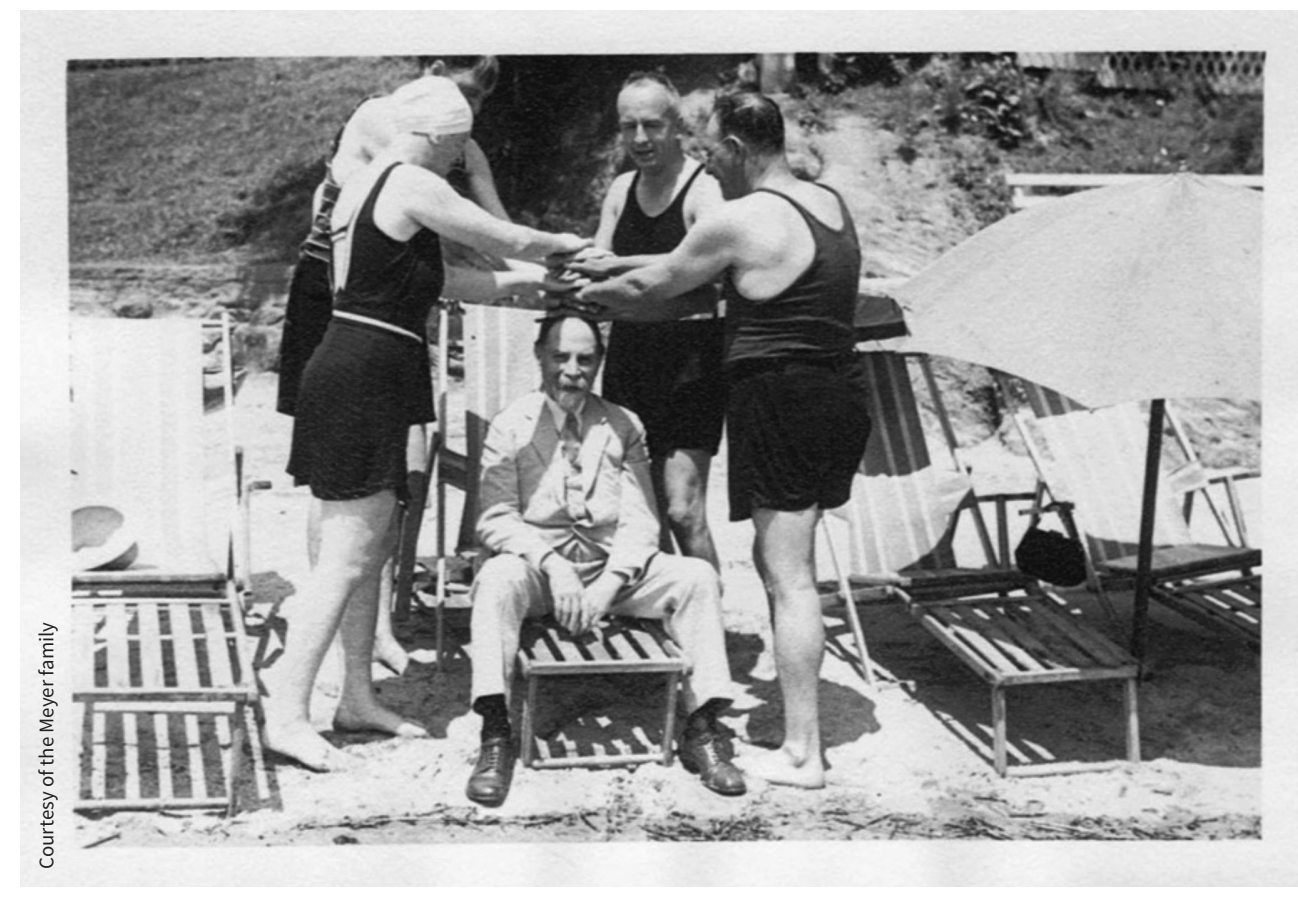

Figure 1: In 1902, Adolf Meyer (seated, with friends in a family photo) called the nervous system the "apparatus of biological plasticity"and placed the concept of neuroplasticity at the centre of his novel theory of psychobiology. Many medical colleagues dismissed the idea as too convoluted. Image published with permission of the Meyer family.

Psychology. James linked plasticity with habit formation: "The phenomena of habit in living beings are due to the plasticity of the organic materials of which their bodies are composed." ${ }^{1}$ Thereafter, the concept of plasticity seeped into philosophy and biology, often without overt acknowledgements of James.

In the 1890s, Meyer recognized that James' concept of biological plasticity was supported by new experimental evidence that showed that nerve cells were not physically connected. The new "neuron doctrine," as it was dubbed by reasonable skeptics at the time, threatened to undermine long-standing research orthodoxies based on mechanical notions of normal and diseased brains. ${ }^{3}$ Along with those of
Santiago Ramón y Cajal (Spanish neuroscientist and pathologist), the experiments of Auguste-Henri Forel (Swiss neuroanatomist, psychiatrist and entomologist who was Meyer's doctoral advisor in Zurich) had helped to confirm the autonomy of neurons. Based on these findings, Meyer set out to reconfigure what he called in 1902 "the apparatus of biological plasticity, the nervous system." 4

Meyer hoped to overturn outdated assumptions about the architecture of the nervous system and causes of neuropsychiatric symptoms. The disease model had led to many life-saving discoveries and to the assumption that all mental abnormalities - from psychosis to dementia to chronic nervousness - 
resulted from distinct lesions or infections. German psychiatrist Emil Kraepelin (who developed a classification system for mental illness that influenced subsequent classifications), Sigmund Freud, the founder of psychoanalysis, and Meyer each pursued alternative theories to anatomic localization as a straightforward explanation for all neuropsychiatric symptoms. All their hypotheses - none of these giants produced experimental evidence were influenced by Darwinian ideas and inspired substantial developments in psychiatry. Neither Kraepelin's nor Freud's conceptual influence, however, emphasized biological integration or the developmental potential of the adult brain. ${ }^{3}$ Meyer, on the other hand, followed James by insisting that the principle of natural selection led inescapably to the conclusion that subjective experience is a causal agent in the human organism's interaction with its external and internal environments. Mental activity, therefore, was a biological function - subject to regulatory and pathological processes. ${ }^{5}$

In 1898, 10 years before his appointment to Johns Hopkins, Meyer proposed a biological theory of mind that he eventually termed "psychobiology." It was a novel reconfiguration of the nervous system that added psychical integration to British neurologist John Hughlings Jackson's hierarchical model of neurology. Meyer's "segmental-suprasegmental" model hypothesized a link between gradual loss of neural segmentation in humans and the centralization of nervous control in the brain, which had emerged anatomically "above" the primitive segmented neural stem. ${ }^{6}$ Meyer presupposed that psychical integration was achieved by means of selective interaction of autonomous neurons, rather than neural anastomosis, which he had earlier noted would allow for the possibility of functional and cellular regeneration in the adult brain. ${ }^{7}$ The theory also reflected the experimental findings of French bacteriologist Émile Roux, who showed that cellular development in embryos is subject to interference and distortion, and those of French physiologist Claude Bernard, who showed that complex organisms maintained self-regulating environments.,

The segmental-suprasegmental model was the foundation of psychobiology, and Meyer's notion that, in humans, psychical integration is expressed at a symbolic level made possible by the unique organization of the human brain. ${ }^{3}$ It was a "valuable discovery by painstaking effort," wrote American psychiatrist and Meyer trainee Theodore Lidz in the 1950s that, despite its incomplete form, constituted "the basis for the scientific extinction of the mind-body dichotomy." ${ }^{8}$ Puzzlingly, Meyer embedded this original contribution in 1898 in a rambling 100page review of international research on neurons. 3,6

Psychobiology became the basis for research, teaching and therapeutics in psychiatry at Johns Hopkins. It conflated the anatomic, neural, mental and behavioural as a single, irreducible sensorimotor response that Meyer deemed a psychobiological reaction. Via these higher reactions, a biological function called mentation integrated and regulated (by means of inhibition) a hierarchy of resources accumulated during human evolution: physiologic systems, instincts, emotions, learning, memory, perception, reasoning, social cooperation and altruism. When mentation no longer functioned optimally, he hypothesized, uninhibited primitive nervous mechanisms successfully competed to respond to social and symbolic stimuli. ${ }^{5}$ Consequently, subjective experience was misinterpreted, which produced symptoms such as anxiety, delusions, obsessions or hallucinations. Theoretically, then, environmental forces - external tactile and internal subjective - could be both causal and therapeutic. ${ }^{3}$

Psychobiology was a working hypothesis that conceptualized the nervous system as an integrated, regulated and openended living process that could not be reduced to predetermined anatomic or physiochemical processes. Within medicine, it was an unorthodox explanation, even as it articulated with the experimental findings of physiologists Charles Sherrington and Walter Cannon, Meyer's direct contemporaries. ${ }^{3,9}$ His famously convoluted explanations of psychobiology stoked doubts about its plausibility and coherence. Meyer acknowledged and lamented the lack of experimental evidence for neuroplasticity, but he remained confident in his theory. "Like every other biological function," he wrote in 1906, "mind can demoralize and undermine itself and its organ (the brain), and the entire biological economy." ${ }^{5}$ For the next 40 years, Meyer urged psychiatrists to reorient the specialty accordingly.

He devised and taught psychobiology to facilitate this reorientation. Its purpose was to synthesize incongruent data, concepts and methods from multiple disciplines - pathology, neurology, physiology, embryology, histology, immunology, bacteriology, psychology, anthropology and sociology - all of which, he insisted, were essential to identify (and potentially influence) the integrated mechanisms of psychiatric disorders. ${ }^{3}$ What psychobiology did not sanction was material or psychical reductionism, which made both psychoanalytically and somatically oriented psychiatrists distrust it. In 1907, Swiss psychiatrist and psychoanalyst Carl Jung reported to Freud that Meyer's ideas were "radical." When Meyer suggested that the leading causes of schizophrenia might be psychogenic, psychiatrist Stanley Abbot was so incensed that he openly criticized the powerful doyen for "reversing the aim of medical science" (i.e., to identify organic etiology). ${ }^{3}$ Psychiatrists on both sides of the mind-body divide disparaged psychobiology and its originator. Eventually, so did historians.

Unlike his clinical and professional reforms, Meyer's theory did not dominate psychiatry in the 20th century. Multidisciplinary and nonreductionist, psychobiology was difficult to explain and impossible to test, which exposed it to criticism and scorn. Meyer's use of the term plasticity, however, was not verbiage - for him, it specified the interfunctionality of neurons and mentation, and the possibility that patients' experiences (normal and pathological) could change their brains and affect clinical outcomes. His program at Johns Hopkins did produce adherents who diligently developed psychobiology. In the 1930s, the Rockefeller Foundation granted millions in research funds based on its promise. ${ }^{3,9}$

Adolf Meyer's ideas and influence created conceptual space in which to imagine and later reimagine neuroplasticity. It is 
often said that history is written by the victors. Now that neuroplasticity has won out, we should re-evaluate its origins. As Tobias Rees showed in his anthropology of neuroplasticity researchers, the evidence required to seriously challenge adult cerebral fixity consolidated only around the year $2000 . .^{10}$ It is understandable, then, why earlier challenges were dismissed or overlooked. Historical reexamination is instructive because it exposes the power of scientific paradigms to obscure the potential of new approaches - in this case, Meyer's efforts to transcend materialism and dualism with a biological framework that integrated mind, body, environment and experience.

\section{Susan Lamb PhD}

Jason A. Hannah Chair in History of

Medicine, Faculty of Medicine, University

of Ottawa, Ottawa, Ont.

\section{References}

1. Berlucchi G, Buchtel HA. Neuronal plasticity: historical roots and evolution of meaning. Exp Brain Res 2009;192:307-19.

2. Fuchs E, Flügge G. Adult neuroplasticity: more than 40 years of research. Neural Plast 2014; 2014:541870.

3. Lamb S. Pathologist of the mind: Adolf Meyer and the origins of American psychiatry. Reprint edition. Baltimore: Johns Hopkins University Press; 2018.

4. Meyer A. Insanity: general pathology. In: Buck $\mathrm{AH}$, editor. Reference Handbook of the Medical Sciences. vol 5. New York: William Wood; 1902;40.

5. Meyer A. Fundamental conceptions of dementia praecox. BMJ 1906;2:757-60.

6. Meyer A. Critical review of the data and general methods and deductions of modern neurology: part 2. J Comp Neurol 1898;8:249-313.

7. Meyer A. A few demonstrations of pathology of the brain and remarks on the problems connected with them. Am J Psychiatry 1895;52:243-9. doi: 10.1176/ajp.52.2.243.

8. Lidz T. Review of the collected papers of Adolf Meyer. Bull Hist Med 1954;28:94-7.

9. Pressman, JD. Human understanding: psychosomatic medicine and the mission of the Rockefeller Foundation. In: Lawrence C, Weisz G, editors. Greater than the parts: holism in biomedicine, 1920-1950. New York: Oxford University Press; 1998;189-210.

10. Rees T. Plastic reason: an anthropology of brain science in embryogenetic terms. Berkeley (CA): University of California Press; 2016.

This article has been peer reviewed.

Competing interests: None declared.

Funding: This research was supported by Associated Medical Services. 